\title{
Measurement of body fat in individuals with tetraplegia: a comparison of eight clinical methods
}

\author{
AM Spungen ${ }^{1}$, WA Bauman ${ }^{1,2}, \mathrm{~J} \mathrm{Wang}^{3}$ and RN Pierson $\mathrm{Jr}^{3}$ \\ ${ }^{1}$ The Spinal Cord Damage Research Center and Departments of Medicine and Rehabilitation Medicine, Mount \\ Sinai Medical Center, New York, NY 10029; ${ }^{2}$ Spinal Cord Injury and Medicine Services, Veterans Affairs \\ Medical Center, Bronx, NY 10468; ${ }^{3}$ Body Composition Unit, Columbia University-St. Luke's/Roosevelt Hospital \\ Center, New York, NY 10025, USA
}

\begin{abstract}
Spinal cord injury (SCI) is a unique condition that markedly alters body composition, raising the possibility of having undefined effects on the traditional assumptions for body composition. In order to determine appropriate methods for the analysis of body composition in this population, 12 subjects with tetraplegia were studied for absolute weight as fat and percent fat by the following methods; bioelectrical impedance (BIA), dual energy X-ray absorptiometry (DEXA), total body potassium (TBK), total body water (TBW), and four anthropometric methods: Durnin and Womersley (DUR), Jackson and Pollack (J and P), Sloan (SLN) and Steinkamp et al (STK). The eight methods were compared with the mean of all means $(24.4 \pm 2.2 \%$ fat $)$, which was assumed to be the best estimate of percent fat. Four methods: BIA, DEXA, TBW and STK were not significantly different, while TBK, DUR, J\&P and SLN were significantly $(P<0.009)$ different from the mean of the means. Using only the non-significantly different methods, repeat computation revealed TBW to have the smallest difference from the mean $(0.1 \pm 2.8 \%)$, and DEXA to have the strongest correlation with the line of identity $(r=0.96$, $P<0.0001)$. In conclusion, BIA, DEXA, TBW, and STK are equally valuable for estimating fat in those with tetraplegia
\end{abstract}

Keywords: spinal cord injury; dual energy X-ray absorptiometry; total body potassium; skinfold measurements; body composition; body fat

\section{Introduction}

Individuals with a spinal cord injury (SCI) undergo body composition changes as a consequence of paralysis. These changes include increases in fat mass and decreases in bone density and lean tissue mass. In previous investigations by our group, a person with tetraplegia, even at ideal body weight for height and age, was found to have on average $22 \%$ more weight as fat than would be expected if the individual had not been injured. ${ }^{1}$ Alterations in body composition such as these may be associated with lipid abnormalities, carbohydrate intolerance and insulin resistance, all of which metabolic perturbations have been reported to occur at a higher frequency in this population. ${ }^{2-8}$ Therefore, valid and reliable quantification of fat tissue is of clinical value for individuals with tetraplegia. None of the current methods of body composition analysis have been validated for use in individuals with SCI. A comparative methodological study is needed in subjects with SCI which uses established methods for measurement of percent fat. In this report, we have performed eight methods for the measurement of body fat content

Correspondence: AM Spungen, Spinal Cord Damage Research Center, Veterans Affairs Medical Center, SCI Service, Room 1E-15, 130 West Kingsbridge Road, Bronx, New York 10468, USA and have made a comparison of their estimates in a group of individuals with tetraplegia.

\begin{abstract}
Methods
Subjects

Twelve Caucasian males with SCI were selected from a total of 38 subjects based on the following criteria. All were healthy individuals with cord transections ranging from vertical levels cervical 4-7. All subjects had complete motor lesions; one subject had a complete sensory lesion and 11 subjects incomplete sensory lesions. Selection criteria for age was $\geqslant 20$ and $\leqslant 40$ years, duration of injury (DOI) was $\geqslant 1$ to $\leqslant 10$ years and weight was not greater than 10 percent of ideal body weight. Ideal body weight (modified to the metric system) was defined as $48.07 \mathrm{~kg}$ for a man of $152.4 \mathrm{~cm}$ in height, and $2.72 \mathrm{~kg}$ for each additional $2.54 \mathrm{~cm} .{ }^{9}$ Institutional review board approval and informed consent was obtained from each subject studied. Physical characteristics and demographic information are presented (Table 1).
\end{abstract}

\section{Body composition measurements}

Bioelectrical impedance analysis (BIA) was measured by use of a tetrapolar impedance plethysmograph 
Table 1 Characteristics of the subjects

\begin{tabular}{lccccc}
\hline $\begin{array}{l}\text { Subject } \\
\text { (number) }\end{array}$ & $\begin{array}{c}\text { Age } \\
\text { (years) }\end{array}$ & $\begin{array}{c}\text { Height } \\
(\mathrm{cm})\end{array}$ & $\begin{array}{c}\text { Weight } \\
(\mathrm{kg})\end{array}$ & $\begin{array}{c}\text { BMI } \\
\left(\mathrm{kg} \mathrm{m}^{-2}\right)\end{array}$ & $\begin{array}{c}\text { DOI } \\
\text { (years) }\end{array}$ \\
\hline 1 & 20 & 185.0 & 73.9 & 21.6 & 4 \\
2 & 35 & 182.9 & 63.9 & 19.1 & 6 \\
3 & 35 & 190.5 & 61.1 & 16.9 & 5 \\
4 & 28 & 170.2 & 54.5 & 18.7 & 5 \\
5 & 21 & 193.0 & 73.5 & 19.7 & 2 \\
6 & 27 & 182.0 & 63.7 & 19.2 & 6 \\
7 & 23 & 178.0 & 83.3 & 26.3 & 2 \\
8 & 38 & 185.3 & 70.3 & 20.3 & 3 \\
9 & 28 & 180.3 & 71.8 & 18.2 & 5 \\
10 & 27 & 167.6 & 54.9 & 19.2 & 2 \\
11 & 38 & 177.8 & 71.7 & 22.6 & 4 \\
12 & 22 & 175.3 & 59.0 & 19.2 & 1 \\
Mean & 28.5 & 180.7 & 66.8 & 20.1 & 3.8 \\
\pm SE & 1.9 & 2.2 & 2.5 & 0.7 & 0.5 \\
\hline
\end{tabular}

$\mathrm{BMI}=$ body mass index $; \mathrm{DOI}=$ duration of injury

and surface electrodes (RJL Systems, Model 101A, Detroit, Michigan) as described by Segal et al..$^{10}$ This method is based on the theory that resistance is proportional to the length/area and composition of the conductor. In the human body, the conductor is water and electrolytes, which are primarily in the fat free mass compartment. The fat compartment of adipose tissue (ie triglycerides) is anhydrous and ion free and, thus, will impede electrical flow. Subjects were asked to lie supine with their shoes and socks removed. Surface electrodes were placed on the dorsal surfaces of the hands and feet. A localized current was transmitted through the body, yielding a measure of total body resistance. The amount of resistance is directly proportional to the relative amount of water in the body, which in turn is proportional to the fat free mass (FFM). FFM is then used with body weight to calculate fat mass (FM) and percent body fat. BIA has been reported to correlate well with total body water, total body potassium, Steinkamp skinfold equations and body densitometry measurements. ${ }^{10-12}$

Dual energy X-ray absorptiometry (DEXA) has recently been developed to measure soft tissue composition in humans. DEXA measurements were made with a total body scanner (model DPX, Lunar Radiation Corp, Madison, Wisconsin) using the methods described by Wang et al, ${ }^{13}$ Heymsfield et al, ${ }^{14}$ and Mazess et al. ${ }^{15}$ Calibration of DEXA consisted of six graded mixtures of lean beef and fat, ranging from 3.7 to $85.6 \%$ fat, as measured by chemical analysis. ${ }^{13}$ The subjects were asked to lie on a table and were whole-body scanned by a congruent beam of stable dual energy radiation (less than $1 \mathrm{mrem}$ ) at two different energy levels (40 and $70 \mathrm{KeV})$, passing through the patient from below while the differential absorption was measured above. The ratio of absorption between the two radiographs of different energies is linearly related to the fat tissue mass in the soft tissue compartment. The procedure for scanning is approximately 30 min in duration and was well tolerated by all subjects studied. DEXA provides a three compartment partition of the body: bone mineral, FM and FFM, DEXA measurements are independent of traditional assumptions of bone density and potassium content.

Total body potassium (TBK) was measured by whole-body ${ }^{40} \mathrm{~K}$ counting using a $4 \mathrm{Pi}$ counting chamber as described by Pierson et al. ${ }^{16,17}$ The subjects were instructed to lie in the whole-body potassium counter for $9 \mathrm{~min}$. The radioisotope ${ }^{40} \mathrm{~K}$, well mixed with the ${ }^{39} \mathrm{~K}$ isotope, occurs naturally in FFM and serves to define the FFM compartment. ${ }^{18,19}$ FFM and percent FFM were determined from total potassium and body weight. Knowledge of FM was then gained by the subtraction of FFM from total body mass. ${ }^{18,19}$

Total body water (TBW) was measured by the dilution of tritiated water corrected for exchangeable hydrogen isotope ${ }^{20}$ with the methods described by Moore et al. ${ }^{21,22}$ This method employs the tracer principle by using the basic formula $V_{2}=C_{1} V_{1} / C_{2}$, where $C_{1}$ and $V_{1}$ are the concentration and volume of the tracer before dilution in the subject, and $\mathrm{C}_{2}$ and $\mathrm{V}_{2}$ are the concentration and volume after injection. FFM and FM were determined from TBW by methods described by Pace et $a l^{23,24}$ with the equation FM $(\mathrm{kg})=$ weight $(\mathrm{kg})-(\mathrm{TBW} / 0.732)$ and $\%$ fat $=[\mathrm{FM}$ $(\mathrm{kg}) /$ weight $(\mathrm{kg})] \times 100$.

\section{Anthropometric measurements}

All anthropometric and skinfold measurements were performed with the use of Lange skinfold calipers and measuring tape (Cambridge Scientific Industries, Cambridge, MD). Skinfold thicknesses and anthropometric measurements were performed on the right side of the body with the subject lying supine, with the exception of those on the back, which were determined with the subject sitting upright. The following anatomical sites were used for the skinfold measurements: biceps, triceps, subscapularis, chest, suprailiac, thorax, umbilicus, abdomen and thigh. Other anthropometric measurements were determined for arm and thigh length, and circumferences for mid-humerus, elbow, wrist, chest, iliac crest and thigh.

Steinkamp et al (STK) developed regression equations using multiple skinfold (SF) and circumference (cir) measurements to estimate fat. These regression equations were developed from body fat measurement as determined by TBK and TBW. These equations are age, race and gender specific. For white males, ages $25-34, \mathrm{FM}(\mathrm{kg})=0.372$ (iliac crest cir) +0.249 (tricep $\mathrm{SF})+0.449$ (thigh cir) +0.38 (thorax SF) -45.464 and for white males ages $35-44, \mathrm{FM}(\mathrm{kg})=0.381$ (waist cir) +0.368 (tricep SF) +0.382 (chest cir) -0.272 (subscapula SF) -51.268 . All other males used FM $(\mathrm{kg})=0.489$ (iliac crest cir) +0.439 (thigh cir) -0.384 (arm length) +0.187 (thorax SF) $-36.165 .^{25,26}$

Durnin and Womersley (DUR) use the sum of four skinfold measurements (biceps, triceps, subscapularis and suprailiac), gender and age to predict percent fat. Percent fat can be determined from these variables using the table provided in their publication. ${ }^{27}$ These variables were determined from linear regression ana- 
lyses with body density measurements from underwater weighing. Percent body fat was calculated from body density (BD) using the equation developed by Siri, $\%$ fat $=[(4.95 / \mathrm{BD})-4.50] 100 .{ }^{28}$

Sloan (SLN) also validated his skinfold measurements on body density determined from underwater weighing using the equation: body density $\left(\mathrm{g} \mathrm{ml}^{-1}\right)=$ $1.1043-0.001327$ (thigh SF) -0.001310 (subscapula SF). ${ }^{29}$ The calculation of body fat from body density (D) was performed by using the equation of Brozek: $\%$ fat $=100(4.57 / \mathrm{D}-4.142) .{ }^{30}$

Jackson and Pollack ( $\mathrm{J}$ and $\mathrm{P}$ ) used body density from underwater weight and residual lung volume to develop the equation body density $=1.09716-$ 0.00065 (chest SF) - 0.00055 (subscapula SF) 0.00080 (thigh SF) for determinations in young adult men. ${ }^{31,32}$ The Siri equation was used to convert body density to \% fat.

\section{Statistical analyses}

All data were analyzed using the STATVIEW software program. Results are expressed as mean \pm SE. The overall mean of all the measurements was considered to be the best estimate of the true value of percent body fat. An overall mean percent body fat was calculated from the eight methods for each subject. Mean differences were calculated for each method minus the overall mean. A simple linear regression analysis was performed between each set of measurements and the overall mean to determine the line of best fit. The proximity of each technique to the mean was determined by comparing the linear regression curve (line of best fit) with the line of identity. Simple linear regression analyses were calculated with each set of measurements as the dependent variable and with the overall mean determination as the independent variable. Four measurement techniques were identified to be not significantly different from the overall mean and they most closely approximated the line of identity. The previous analyses were repeated with only those four methods (BIA, DEXA, STK and TBW). The mean percent body fat of the four methods was calculated. Simple linear regressions between the mean of the four methods and each set of variables were recalculated.

\section{Results}

The individual, mean values by subject, mean values by method, mean difference and correlation coefficients for percent body fat and body fat weight $(\mathrm{kg})$ are reported (Tables 2,3 ). The ranges of percent fat and fat weight for the subjects were $13.0 \pm 3.0$ to $37.5 \pm 5.0 \%$ and $9.32 \pm 2.18$ to $31.20 \pm 4.20 \mathrm{~kg}$. The ranges of percent fat and absolute fat weight were lowest by $\mathrm{J}$ and $P$ with $12.1 \pm 1.5 \%$ fat and $8.14 \pm 1.12 \mathrm{~kg}$, and highest by TBK with $49.1 \pm 2.5 \%$ fat and $32.9 \pm 2.5 \mathrm{~kg}$. The average percent fat and fat weight (overall mean $\pm \mathrm{SE}$ for all eight methods) for the group was $24.4 \pm 2.2 \%$ and $16.50 \pm 2.69 \mathrm{~kg}$. For percent fat, the correlation coefficients among the methods and the mean values are greater than 0.76 , demonstrating good correlation with all techniques (Table 2). BIA was the closest method to the mean of the means, with a slight overestimation of the mean \pm SE by $0.55 \pm 1.0 \%$ fat (Table 2). TBK had the largest difference from the mean of the means with an overestimation of fat by $24.7 \pm 1.2 \% \quad(P<0.001)$ (Table 2$)$. The STK et al method, with an average difference of $1.14 \pm 1.8 \%$ fat, was the closest anthropometric measurement to the

Table 2 Results of percent body fat by subject and method

\begin{tabular}{|c|c|c|c|c|c|c|c|c|c|}
\hline Subject & $T B W$ & $B I A$ & $D E X A$ & $T B K$ & $S T K$ & DUR & $S L N$ & $J$ and $P$ & Mean $\pm S E$ \\
\hline 1 & 29.2 & 26.5 & 41.1 & 55.3 & 45.6 & 26.3 & 18.8 & 14.6 & $32.2 \pm 4.9$ \\
\hline 2 & 20.3 & 24.2 & 30.0 & 43.7 & 23.8 & 21.7 & 10.8 & 12.3 & $23.4 \pm 3.7$ \\
\hline 3 & 26.0 & 17.5 & 17.9 & 52.6 & 21.5 & 15.0 & 7.2 & 8.3 & $20.8 \pm 5.1$ \\
\hline 4 & 23.7 & 14.2 & 21.9 & 46.4 & 16.7 & 9.8 & 9.2 & 8.6 & $18.8 \pm 4.4$ \\
\hline 5 & 26.7 & 24.4 & 21.7 & 49.5 & 21.2 & 14.1 & 12.9 & 10.1 & $22.6 \pm 4.4$ \\
\hline 6 & 23.9 & 19.4 & 19.3 & 45.7 & 16.6 & 11.0 & 7.2 & 5.1 & $18.5 \pm 4.5$ \\
\hline 7 & 43.6 & 39.9 & 44.0 & 64.4 & 35.9 & 30.1 & 22.6 & 19.1 & $37.5 \pm 5.0$ \\
\hline 8 & 10.4 & 11.6 & 15.1 & 35.8 & 24.6 & 14.1 & 11.3 & 8.9 & $16.5 \pm 3.3$ \\
\hline 9 & 8.3 & 10.0 & 12.9 & 32.8 & 14.4 & 12.6 & 7.7 & 5.1 & $13.0 \pm 3.0$ \\
\hline 10 & 25.8 & 31.3 & 28.5 & 48.5 & 32.5 & 18.5 & 17.2 & 16.9 & $27.4 \pm 3.7$ \\
\hline 11 & 32.9 & 34.2 & 33.4 & 53.3 & 34.4 & 25.9 & 19.3 & 17.0 & $31.3 \pm 4.0$ \\
\hline 12 & 34.7 & 33.3 & 32.3 & 61.2 & 19.6 & 21.7 & 28.3 & 19.2 & $31.3 \pm 4.8$ \\
\hline Mean & 25.5 & 23.9 & 26.5 & 49.1 & 25.6 & 18.4 & 14.4 & 12.1 & $24.4 \pm 4.0$ \\
\hline$\pm \mathrm{SE}$ & 2.8 & 2.8 & 2.9 & 2.7 & 2.7 & 1.9 & 2.0 & 1.5 & \pm 2.2 \\
\hline Corr coef & 0.90 & 0.95 & 0.96 & 0.89 & 0.76 & 0.91 & 0.87 & 0.93 & \\
\hline Mean diff & 1.04 & -0.55 & 2.08 & $24.68^{*}$ & 1.14 & $-6.02^{*}$ & $-10.05^{*}$ & $-12.32^{*}$ & \\
\hline$\pm \mathrm{SE}$ & 1.3 & 1.0 & 1.0 & 1.2 & 1.8 & 0.9 & 1.1 & 1.0 & \\
\hline
\end{tabular}

*Significantly different from the mean $(P<0.01)$

Corr coef $=$ correlation coefficient of each method with the overall mean

Mean diff $=$ mean difference (method minus the mean) 
Table 3 Results of fat weight $(\mathrm{kg})$ by subject and method

\begin{tabular}{lrrrrrrrrr}
\hline Subject & $T B W$ & \multicolumn{1}{c}{ BIA } & DEXA & $T B K$ & \multicolumn{1}{c}{$S T K$} & DUR & \multicolumn{1}{c}{$S L N$} & J and P & Mean $\pm S E$ \\
\hline 1 & 21.58 & 19.58 & 30.37 & 40.87 & 33.70 & 19.44 & 13.89 & 10.79 & $23.78 \pm 3.64$ \\
2 & 12.97 & 15.46 & 19.17 & 27.92 & 15.21 & 13.87 & 6.90 & 7.86 & $14.61 \pm 2.51$ \\
3 & 15.89 & 10.69 & 10.94 & 32.14 & 13.14 & 9.16 & 4.40 & 5.07 & $12.99 \pm 2.99$ \\
4 & 12.92 & 7.74 & 11.94 & 25.29 & 9.10 & 5.34 & 5.01 & 4.69 & $10.25 \pm 2.41$ \\
5 & 19.62 & 17.93 & 15.95 & 36.38 & 15.58 & 10.36 & 9.48 & 7.42 & $16.59 \pm 3.21$ \\
6 & 15.22 & 12.36 & 12.29 & 29.11 & 10.57 & 7.01 & 4.59 & 3.25 & $11.80 \pm 2.87$ \\
7 & 36.32 & 33.24 & 36.65 & 53.65 & 29.90 & 25.07 & 18.83 & 15.91 & $31.20 \pm 4.20$ \\
8 & 7.31 & 8.15 & 10.62 & 25.17 & 17.29 & 9.91 & 7.94 & 6.26 & $11.58 \pm 2.29$ \\
9 & 5.96 & 7.18 & 9.26 & 23.55 & 10.34 & 9.05 & 5.53 & 3.66 & $9.32 \pm 2.18$ \\
10 & 14.16 & 17.18 & 15.65 & 26.63 & 17.84 & 10.16 & 9.44 & 9.28 & $15.04 \pm 2.06$ \\
11 & 23.59 & 24.52 & 23.95 & 38.22 & 24.66 & 18.57 & 13.84 & 12.19 & $22.44 \pm 2.85$ \\
12 & 20.46 & 19.63 & 18.98 & 36.08 & 11.55 & 12.79 & 16.68 & 11.32 & $18.44 \pm 2.84$ \\
Mean & 17.17 & 16.14 & 17.98 & 32.92 & 17.41 & 12.56 & 9.71 & 8.14 & $16.50 \pm 1.87$ \\
\pm SE & 2.33 & 2.22 & 2.46 & 2.51 & 2.30 & 1.67 & 1.43 & 1.12 & \pm 2.69 \\
Mean diff & 0.67 & -0.36 & 1.48 & $16.42^{*}$ & 0.91 & $-3.94^{*}$ & $-6.79^{*}$ & $-8.36^{*}$ & \\
\pm SE & 2.33 & 2.22 & 2.46 & 2.51 & 2.30 & 1.67 & 1.43 & 1.12 & \\
\hline
\end{tabular}

*Significantly different from the mean $(P<0.01)$

Mean diff $=$ mean difference $($ method minus the mean)

mean of the means (Table 2). The other anthropometric methods, DUR, SLN and $J$ and $P$ all significantly $(P<0.01)$ underestimated the mean percent fat (Table 2).

The results of the simple linear regression analysis for each method and the mean of the means (Table 4), and each method and the line of identity (Figure 1), are reported. The methods of BIA, DEXA, TBW and STK demonstrated the strongest correlations to the line of identity.

In order to obtain a truer representation of percent body fat, those methods which were significantly different from the mean of the means were eliminated from the analysis. A new mean of the means was calculated using only the four methods (BIA, DEXA, TBW and STK) which were not significantly different from the original mean of the means. A comparison of the four methods with this new mean $(25.4 \pm 2.5)$ for percent fat, revealed that TBW was the closest method with a difference of $0.1 \pm 2.8 \%$ body fat, while DEXA had the strongest correlation $(r=0.96, P<0.0001)$.

\section{Conclusions}

Most body composition methods are based on equations that use constants representative of a cross section of the population being studied. For example, underwater weighing uses bone density equations based on standards developed from healthy ambulatory individuals. The mean $\pm S E$ total body bone mineral density in our group of subjects was $81 \pm 4 \%$ of predicted, which would cause considerable overestimation of fat tissue by the underwater weighing method. In addition, for hydrodensitometry to be performed reliably, the lung volume measurement is critical. Paralysis of the muscles which assist in forced efforts of inspiration and expiration (scalenes, abdominals, external and internal intercostals) occurs with tetraplegia, causing unpredictable impairment of exhalation to residual volume, further invalidating the underwater weighing method. George et al, ${ }^{33}$ in part, addressed this issue by investigating the validity of hydrodensitometry for determination of body composition in

Table 4 Results of regression analysis for percent fat

\begin{tabular}{|c|c|c|c|c|c|c|}
\hline Method & $r$ & $S E$ & $P$ & Slopes & Intercepts & $95 \% C I$ \\
\hline TBW & 0.90 & 0.180 & 0.0001 & 1.173 & -3.19 & $23-28$ \\
\hline BIA & 0.95 & 0.129 & 0.0001 & 1.220 & 1.22 & $22-26$ \\
\hline DEXA & 0.96 & 0.123 & 0.0001 & 1.284 & 1.28 & $25-28$ \\
\hline TBK & 0.89 & 0.176 & 0.0001 & 1.070 & 22.06 & $46-52$ \\
\hline STK & 0.76 & 0.261 & 0.004 & 0.971 & 1.86 & $21-30$ \\
\hline DUR & 0.91 & 0.117 & 0.0001 & 0.814 & -1.47 & $17-20$ \\
\hline SLN & 0.87 & 0.145 & 0.0003 & 0.792 & -4.96 & $12-17$ \\
\hline $\mathrm{J} \& \mathrm{P}$ & 0.93 & 0.082 & 0.0001 & 0.640 & -3.52 & $11-13$ \\
\hline
\end{tabular}

Results of regression analysis for the overall mean and each method $(24.4 \pm 2.2 ; n=12$ and methods $=8)$. 


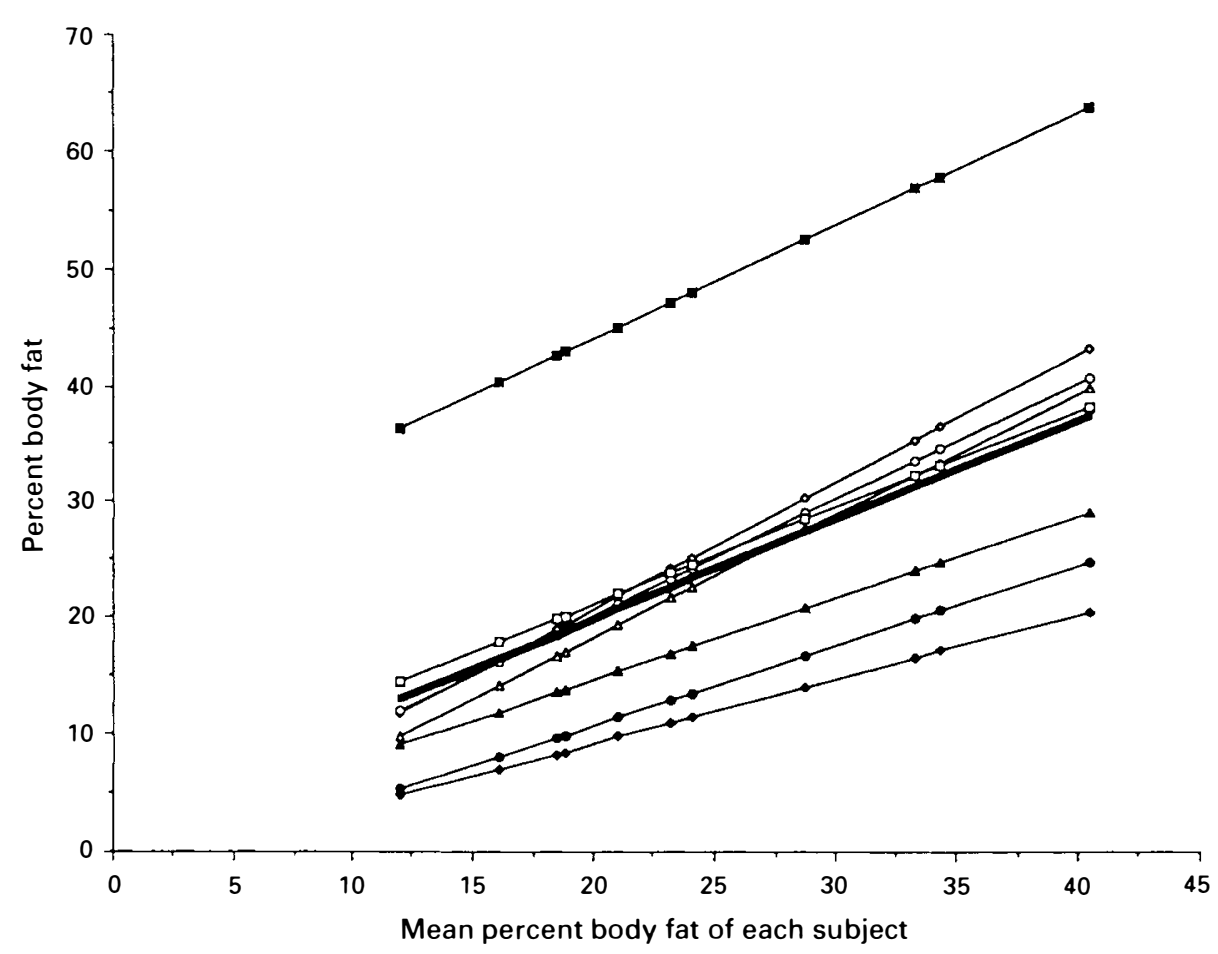

Figure 1 The linear regression line by method for each subject is represented by: closed squares $(\boldsymbol{\square})=$ total body potassium (TBK); open diamonds $(\diamond)=$ dual energy X-ray absorptiometry (DEXA); open circles $(\bigcirc)=$ total body water (TBW); open triangles $(\triangle)=$ bioelectrical impedance $($ BIA $)$; open squares $(\square)=$ Steinkamp skinfold $(\mathrm{STK})$; solid line $(-)=$ line of identity; closed triangles $(\boldsymbol{\Delta})=$ Durnin and Wormersly skinfold $($ DUR); closed circles $(\boldsymbol{O})=$ Sloan skinfold $(\mathrm{SLN})$; closed diamonds $(\nabla)=$ Jackson and Pollack skinfold (J and P). Subjects 11 and 12 had the same mean percent fat resulting in overlapping data points, thus only eleven points appear to be represented

subjects with SCI. Because of this lack of validity, and the difficulty of performing the technique in those with tetraplegia, hydrodensitometry was not chosen as a method of percent fat analysis in this investigation. Of note, the three skinfold methods which were validated using underwater weight for body density (DUR, J and $P$ and SLN) were each found to be significantly different from the mean of the means.

After SCI, tissues of the lower extremities undergo the most significant changes. The skinfold measurements of Durnin and Womersley and Jackson and Pollack do not incorporate a lower extremity measurement in their equations. Sloan uses a thigh skinfold thickness measurement and Steinkamp uses a thigh circumference measurement. In paralyzed individuals who are likely to have increased regional (lower extremity) adiposity, the inclusion of the thigh circumference measurement in the Steinkamp et al equation may have partially contributed to the closeness to the mean percent fat. However, it is more likely that the validation method (TBK and TBW) used by Steinkamp et al had a more significant impact on these results than the other three anthropometric methods which were validated against underwater weighing.

TBK may be inaccurate in subjects with SCI. In normally innervated lean tissue, there is a relative constant amount of potassium $(\mathrm{K})$ within skeletal muscle $\left(140 \mathrm{mEql}^{-1}\right.$ intracellular water), and a resul- tant average of $\mathrm{K}$ content in the lean body cell of $68.1 \mathrm{mEq} \mathrm{kg}{ }^{-1} \cdot{ }^{13,17,34}$ Other lean tissue compartments generally have a lower average $\mathrm{K}$ content. ${ }^{35}$ Since skeletal muscle is the major contributor to the $\mathrm{K} / \mathrm{fat}$ free mass (FFM) ratio, and this compartment is selectively lost or pertubated as a result of paralysis, then potassium per $\mathrm{kg}$ of lean tissue is significantly reduced in individuals with spinal cord injury. ${ }^{36}$ Therefore, FFM will be markedly underestimated by the TBK constant, and thus fat mass will be overestimated. As we reported herein, percent fat by TBK displayed the largest difference from the mean percent fat of the group.

Shizgal et al $^{37}$ reported body composition measurements by a TBW method using multiple isotope dilution with tritium, sodium, and potassium in 12 tetraplegia patients with a mean duration of injury of about 15 months. The group with tetraplegia was subdivided on the basis of the relationship of body cell mass (BCM) to extracellular mass (ECM) into normally nourished $(\mathrm{BCM}=\mathrm{ECM}, n=5)$ and malnourished (BCM $<$ ECM, $n=7)$ subgroups. Percent body fat for the normally nourished subgroup was 24.1 , and the malnourished subgroup, 29.2. Body potassium was decreased in both, but significantly more so in the malnourished subjects. The findings of Shizgal et al of $24.1 \%$ body fat, by TBW measurement in the normally nourished group is similar to the TBW data presented 
in this report of an average percent body fat of 25.5 . Rasmann Nuhlicek et al $^{38}$ subdivided subjects according to 'high' and 'low' tetraplegia (HQ and LQ, respectively) with durations of injury ranging from 1 to over 20 years. The HQ subgroup $(n=8)$ used electric wheelchairs and the LQ subgroup $(n=11)$ were able to use manual wheelchairs. Employing a more conventional TBW method using dilution of tritium, body composition was measured in 19 healthy males with tetraplegia. For HQ percent fat was 32.3 and for LQ, 35.7 , both were significantly greater than the control group at $21.9 \%$. These findings are also about $8.5 \%$ higher on average for total body fat than our results, which may be attributed to differences in body weight. The average weight and height was $71.8 \mathrm{~kg}$ and $181.4 \mathrm{~cm}$ for the HQ and LQ in the Rassmann Nuhlicek et al study versus a weight of $66.8 \mathrm{~kg}$ and height of $180.7 \mathrm{~cm}$ in our study.

BIA is a method based on the specific electrical characteristics of biological tissue. The reliability of this technique, in theory, should not be altered with SCI, therefore providing an accurate assessment of body fat. In our findings, BIA was closest to the mean of the means in estimating fat. However, BIA is not without its limitations. Cross validation studies have shown large variability in the within-subject measurements, causing small changes within a group to be obscured. ${ }^{12}$

DEXA, a purely physical method, measures the soft tissue by the attenuation of fat to fat free mass. Improvements in the reproducibility of the DEXA measurement by use of a meat calibration technique has led to a measurement precision of $< \pm 1 \%$ for fat for in vivo standards. ${ }^{13,33}$ Because of this calibration technique, DEXA is able to bypass traditional assumptions for fat content assessment, and may have the least intrinsic sources of error for measurement of fat in those with SCI. Heymsfield et al demonstrated a strong correlation between fat measured by gadolinium dual photon absorptiometry (a hardware predecessor to DEXA) and four existing methods; hydrodensitometry, total body water, total body potassium, and neutron activation analysis. ${ }^{14} \mathrm{Heymsfield}$ et al caution that questions regarding the accuracy of DEXA in obese, hyper- or hypohydrated patients remain unanswered. ${ }^{4}$

In summary, three of the eight methods studied by our group (SLN, DUR, and J and P) rely on underwater weighing for validation and/or calibration. Three more of the eight measurements (TBK, TBW and STK) are based on assumptions that may not be valid in those with SCI. Modern technology has led to several innovative, increasingly accurate and precise techniques. DEXA and BIA determine the fat mass compartment independent of traditional assumptions. From our study, TBW, BIA, DEXA and STK skinfold equations were equally valuable methods for measurement of fat mass in individuals with tetraplegia. However, at present, in vivo body composition measurements have intrinsic limitations when applied to the general population, as well as unique groups, including those with SCI. Additional methodologies independent of traditional assumptions may be useful for the determination of body composition, as well as the validation of existing methods, in subjects with spinal cord injury.

\section{Acknowledgements}

This research was supported by the Veterans Affairs Merit Review Program; Eastern Paralyzed Veterans Association; The Veterans Affairs Medical Center, Bronx, NY; and The Mount Sinal Medical Center, New York, NY.

\section{References}

1 Spungen AM, Bauman WA, Wang J, Pierson Jr RN. Quantification of adiposity by dual photon $\mathrm{x}$-ray absorptiometry in individuals with paraplegia or quadriplegia. J Am Paraplegia Soc 1992; 16: 55.

2 Bauman WA, Spungen AM. Disorders of carbohydrate and lipid metabolism in veterans with paraplegia or quadriplegia: a model of premature aging. Metabolism 1994; 43: 749-756.

3 Bauman WA et al. Depressed serum high density lipoprotein cholesterol levels in veterans with spinal cord injury. Paraplegia 1992; 30: 697-703.

4 Bauman WA. The endocrine system. In: Whiteneck GG, Mentor R (eds). Aging with Spinal Cord Injury. Demos Publications: New York, NY, pp 139-157.

5 LaPorte RE et al. HDL cholesterol across a spectrum of physical activity from quadriplegia to marathon running. Lancet 1983; 1: 1212-1213.

6 Brenes $\mathrm{G}$ et al. High density lipoprotein cholesterol concentrations in physically active and sedentary spinal cord injured patients. Arch Phys Med Rehabil 1986; 67: 445-450.

7 Bauman WA et al. Coronary artery disease: metabolic risk factors and latent disease in individuals with paraplegia. $M t$ Sinai J Med 1992; 59: 163-168.

8 Duckworth WC et al. Glucose intolerance due to insulin resistance in patients with spinal cord injuries. Diabetes 1980; 29: $906-910$.

9 Zeman FJ. In: Jones L (ed). Clinical Nutrition and Dietetics, 2nd edn. Macmillian Publishing Company: New York, NY, 1991, p 51.

10 Segal KR et al. Estimation of human body composition by electrical impedance methods: a comparative study. J Appl Physiol 1985; 58: 1565-1571.

11 Segal KR et al. Lean body mass estimation by bioelectrical impedance analysis: a four-site validation study. Am J Clin Nutr 1988; 47: 7-14.

12 Lukaski HC. Body composition assessment using impedance methods. In: Bjorntorp, Brodorff (eds). Obesity. JB Lippincott Company: Philadelphia, PA, 1992, pp 67-79.

13 Wang $\mathrm{J}$ et al. Body fat from body density: underwater weighing vs. dual-photon absorptiometry. Am J Physiol 1989; 256 (Endocrinol Metab 19): E829-E834.

14 Heymsfield SB et al. Dual-photon absorptiometry: comparison of bone mineral and soft tissue mass measurements in vivo with established methods. Am J Clin Nutr 1989; 49: 1283-1289.

15 Mazess RB, Peppler WW, Gibbons M. Total body composition by dual photon absorptiometry. Am J Nutr 1984; 40: 834-839.

16 Pierson $\mathrm{RN} \mathrm{Jr}$ et al. Body potassium by four-Pi ${ }^{40} \mathrm{~K}$ counting: an anthropometric correction. Am J Physiol 1984; 246: F234-239.

17 Pierson RN Jr et al. Body composition measurements in normal man: Potassium, saline and tritium spaces in 58 adults. $J$ Chron Dis 1982; 35: 419-428.

18 Forbes GB, Gallup J, Hirsch JB. Estimation of total body fat from potassium ${ }^{40}$ content. Science 1961; 133: 101-102.

19 Forbes GB, Schultz F, Cefarelli C, Amishakimi GH. Effects of body size on potassium ${ }^{40}$ measurements in the whole body counter (tilt-chair technique). Health Phys 1968; 15: 435-422. 
20 Culebars JM, Moore FD. Total body water and exchangeble hydrogen I. Theoretical calculation of non aquious exchangeable hydrogen in man. Am J Physiol 1977; 232: R54-R59.

21 Moore FD. Determination of total body water and solids with isotopes. Science 1946; 104: 157-160.

22 Moore FD et al. The Body Cell Mass and its Supporting Environment: Body Composition in Health and Disease. WB Saunders: Philadelphia, PA, 1963, pp 157-159.

23 Pace N, Rathbun EN. Studies on body composition: Body water and chemically combined nitrogen content in relation to fat content, part III. J Biol Chem 1945; 158: 685-691.

24 Rathbun EN, Pace N. Studies on body composition: the determination of total body fat by mean of the body specific gravity, part I. J Biol Chem 1945; 158: 667-676.

25 Steinkamp RC et al. Measures of body fat and related factors in normal adults. I. J Chron Dis 1965; 18: 1279-1291.

26 Steinkamp RC, Cohen NL, Gaffey WR. Measures of body fat and related factors in normal adults. II. J Chron Dis 1965; 18: 1291-1307.

27 Durnin JGVA, Womersley J. Body fat assessed from total body density and its estimation from skinfold thickness: measurements on 481 men and women aged from 16 to 72 years. $\mathrm{Br} \mathrm{J}$ Nutr 1974; 32: 77-97.

28 Siri WE. Body composition from fluid spaces and density: analysis of methods. UCRL-3349, University of California, Berkley, CA, 1956.
29 Sloan AW. Estimation of body fat in young men. J Appl Phys 1967; 23: 311-315.

30 Brozek J, Grande F, Anderson JT, Keys A. Densitometric analysis of body composition: revision of some quantitative assumptions. Ann NY Acad Sci 1963; 110: 113-140.

31 Jackson AS, Pollock ML. Prediction accuracy of body density, lean body weight, and total body volume equations. Med Sci Sports 1977; 9: 197-201.

32 Pollack ML et al. Prediction of body density in young and middle-aged men. J Appl Physiol 1976; 40: 300-304.

33 George CM, Wells CL, Dugan NL. Validity of hydrodensitometry for determination of body composition in spinal cord injured subjects. Hum Biol 60: 771-780.

34 Pierson RN Jr et al. Measuring body fat: calibrating the rulers. Intermethod comparisons in 389 normal Caucasian subjects. Am J Physiol 1991; 261 (Endocrinol Metab 24) E103-E108.

35 International Commission of Radiological Protection. Gross and elemental content of reference man. Report of the Task Group on Reference Man, No. 23. Pergamon Press: New York, 1974, pp 273-334.

36 Spungen AM, Bauman WA, Wang J, Pierson Jr, RN. Reduced quality of fat free mass in paraplegia. Clin Res 1992; 40: 280A.

37 Shizgal HM et al. Body composition in quadriplegic patients. J Parenter Enter Nutr 1986; 10: 364-368.

38 Rasmann Nuhlicek DN. Body composition of patients with spinal cord injury. Eur J Clin Nutr 1988; 42: 765-773. 